Revista Española de Antropología Americana

ISSN: 0556-6533

https://dx.doi.org/10.5209/reaa.72773

\title{
Colonialismo, Antropología y reemergencias indígenas en Tierra del Fuego
}

\author{
Ana Cecilia Gerrard ${ }^{1}$
}

Recibido: 2 de diciembre de 2020 / Aceptado: 2 de febrero 2021

Resumen. En este trabajo analizaré la reemergencia del Pueblo Selk'nam en Tierra del Fuego (Argentina); un territorio que desde los albores de la colonización llevada a cabo por los Estados argentino y chileno ha sido imaginado como blanco y europeo, como un sitio donde ya no habría indígenas. La reemergencia de los selk'nam y los yaganes, su presencia en la arena pública y el avance de sus agendas políticas en los últimos treinta años, tensionan las narrativas fundacionales del territorio provincial y cuestionan el lugar de la Antropología en la extinción discursiva de estos pueblos.

Palabras clave: Pueblo Selk’nam; colonialismo de pioneros; Antropología; etnogénesis; reemergencia indígena; Tierra del Fuego (Argentina).

\section{[en] Colonialism, Anthropology and Indigenous Reemergences in Tierra del Fuego}

\begin{abstract}
This paper discusses the reemergence of Selk'nam People in Tierra del Fuego (Argentina), a territory that since the beginning of colonization carried out by the Argentine and Chilean states, has imagined itself as white and European, as one without indigenous inhabitants. The re-emergence of Selk'nam and Yagan People, their ontological presence and the advancement of their political agendas in the last thirty years stress the founding narratives of the provincial territory and question the place of Anthropology in the rhetorical extinction of indigenous people.

Keywords: Selk'nam People; Settler colonialism; Anthropology; Ethnogenesis; Indigenous re-emergence; Tierra del Fuego (Argentina).

Sumario: 1. Introducción. 2. Etnogénesis, resurgimiento y reemergencias indígenas. 3. Traumas, fantasmas y el retorno de lo reprimido. 4. Arqueologización, culturalismo y resistencias. 5. Reflexiones finales. 6. Referencias.
\end{abstract}

Cómo citar: Gerrard, Ana Cecilia. 2021. "Colonialismo, Antropología y reemergencias indígenas en Tierra del Fuego". Revista Española de Antropología Americana 51: 231-243.

\section{Introducción ${ }^{2}$}

La ciencia, el Estado y las misiones religiosas han cristalizado la imagen de la extinción de los selk'nam y los yaganes, que en el relato oficial de la Historia regional habría ocurrido a fines del siglo XIX y principios del XX, puesto que la colonización

1 Instituto de Cultura, Sociedad y Estado, Universidad Nacional de Tierra del Fuego, CONICET. cgerrard@untdf. edu.ar.

2 Quiero agradecer a Mariela Eva Rodríguez por la apertura generosa y por el viaje que hace unos años me invitó a emprender, junto a Celina San Martín, hacia puertos muchas veces imprevistos. A Miguel Pantoja por todos estos años de caminos entreverados que recorrimos a través de huellas cercanas y distantes. A Rodrigo Pascual por su lectura atenta y sus aportes. A los pueblos selk’nam y yagan, presentes y en lucha más allá de las fronteras. 
trajo consigo cambios radicales que fueron percibidos como irremediables. Si bien estos cambios implicaron una experiencia traumática de discontinuidad (colapso demográfico, persecuciones, matanzas y despojo), en los últimos treinta años asistimos a la experiencia de reemergencia de esos mismos pueblos que la Antropología había dado por muertos. Sin embargo, estas rupturas críticas que la ciencia hegemónica concibe como un "antes" y un "después" son interpretadas en el marco de regímenes de historicidad indígenas que perciben estos procesos como una continuidad, y es por esto que son los mismos pueblos quienes reclaman su preexistencia y permanencia en el territorio insular de Tierra del Fuego.

Al establecer la división artificial entre el mundo moderno y la "prehistoria" marcada por una vara temporal etnocéntrica, cronocéntrica y ahistórica, que muy poco tiene de natural y objetiva- la Antropología, entendida como una institución cultural occidental y moderna ${ }^{3}$, y la Historia han ubicado a los selk'nam y los yaganes en la prehistoria y, en este movimiento, les han negado legitimidad y la posibilidad de existir en presente. Más aún, estas disciplinas contribuyeron -junto con el arte, la literatura y otras ramas de la ciencia- a forjar y cristalizar las narrativas de la nación. Sin embargo, la lógica universal del tiempo lineal y cronológico es desafiada por las narrativas indígenas. Dichas narrativas cuestionan el relato estático y sacralizado por el poder, e insisten en que el Estado y la sociedad en general los consideren como sujetos contemporáneos; sujetos que emprenden una suerte de "viaje de vuelta", tal es el término utilizado por João Pacheco de Oliveira (2004), para enfrentarse con las "tachaduras" producidas por la violencia del genocidio y la colonización".

Este artículo presenta una clave de lectura del proceso de reemergencia del Pueblo Selk'nam en Tierra del Fuego. En primer lugar, y después de analizar los conceptos de etnogénesis, reemergencia y resurgimiento, planteo un acercamiento al contexto en el que los indígenas reemergen como tales. A continuación, analizaré el lugar de la ciencia, en particular el impacto de las prácticas y las teorizaciones de la Antropología en la extinción discursiva de los indígenas. Finalmente revisaré algunas instancias en las que los selk'nam manifiestan su resistencia y oposición ante este orden de cosas.

\section{Etnogénesis, resurgimiento y reemergencias indígenas}

La visibilización creciente de los selk’nam y los yaganes, y su organización en comunidades $^{5}$, se enmarca dentro de lo que Jonathan Hill (2009: 25) denomina como

3 La Antropología se divide en diferentes subcampos, como Antropología Biológica, Antropología Social y Arqueología, entre otros.

4 El concepto "tachadura" proviene de las lecturas deconstructivistas de Jaques Derrida en sus diálogos con Heidegger y Nietzsche. Este término plantea que el signo está habitado por huellas de otros signos que no se presentan como tales, tal y como sostiene Spivak (2013). En línea con el trabajo de Rodríguez et al. (2016) y con los argumentos desplegados en este artículo, puedo afirmar que los pueblos indígenas de Tierra del Fuego han sido "tachados" en las narrativas fundacionales, al ser nombrados de acuerdo con las imágenes etnográficas proyectadas por la Antropología; proceso a través del cual fueron convertidos en fantasmas. Sin embargo, tal y como explican las autoras, como la lectura "bajo borradura" permite reconstruir las huellas de la materialidad del signo -"la cadena consecutiva de técnicas que vinculan procesos de archivamiento con archivadores funcionales a la hegemonía, a los cuales la materialidad misma de los documentos ha estado sometida" (Rodríguez et al. 2016: 112)-cuando los lectores son indígenas, dichas lecturas "pueden actuar sobre imágenes internalizadas y modificar las memorias disponibles" (ibíd.) y ser, al mismo tiempo, una negación de su negación y, en consecuencia, una liberación de los espectros.

5 La Comunidad Indígena Rafaela Ishton del Pueblo Selk'nam fue reconocida por el Estado argentino en el año 1995 cuando obtuvo la personería jurídica tras la inscripción en el Registro Nacional de Comunidades Indíge- 
"etnogénesis", es decir, un proceso de reconstrucción auténtica de nuevas identidades sociales a través del redescubrimiento creativo y la remodelación de componentes de la "tradición" en contextos de cambios radicales y discontinuidades. En una compilación de ensayos producida anteriormente por el mismo autor (Hill 1996), el concepto de "etnogénesis" es el eje que articula una serie de trabajos que analizan las variadas formas en que los indígenas y los afrodescendientes en el continente americano se organizaron colectivamente, en respuesta a las condiciones socioeconómicas y políticas que enfrentaron y enfrentan. Allí, la etnogénesis es definida en una doble acepción, como "una herramienta analítica para desarrollar enfoques históricos críticos de la cultura como un proceso continuo de lucha y conflicto por la existencia de un pueblo y su posicionamiento dentro y contra una historia general de dominación" y como un concepto general que remite a procesos de "adaptación creativa a la historia general de cambios violentos que incluyen colapsos demográficos, relocalizaciones forzadas (...) genocidio y etnocidio que fueron impuestos durante la expansión de los Estados coloniales y nacionales en América” (Hill 1996: 1).

Los trabajos incluidos en la compilación de Hill recurren a diferentes definiciones del concepto en los casos que analizan, todos ellos enfocados en pensar estos procesos como respuestas o resistencias al poder del Estado y en los efectos de las políticas estatales orientadas a los colectivos subalternizados. Sin embargo, mientras que para Hill tal articulación se da a partir de un concepto que enfatiza en las resistencias activas, para otros autores, la etnogénesis no remite necesariamente a un proceso de resistencia en términos tradicionales, sino a una necesidad práctica y a estrategias posibles frente a un entorno hostil, como es el caso de las aproximaciones etnohistóricas de Sattler y Whitehead en dicho volumen (Hill 1996).

Con algunas diferencias conceptuales, Miguel Bartolomé (2003) distingue entre los procesos de etnogénesis y los de "revitalización étnica"6. Este autor ha sido uno de los primeros antropólogos en advertir la presencia del Pueblo Selk'nam de Tierra del Fuego en el ámbito público en el siglo XXI, aunque no hizo trabajo de campo con ellos. Explica que su "aparición" es producto de un proceso de etnogénesis, a la que define, en este caso, como "procesos de actualización identitaria de grupos étnicos que se consideraban cultural y lingüísticamente extinguidos y cuya emergencia contemporánea constituye un nuevo dato, tanto para la reflexión antropológica como para las políticas públicas en contextos multiculturales" (Bartolomé 2003: 175).

Sin embargo, un problema del concepto restringido de etnogénesis entendido de este modo es el énfasis en la perspectiva de la teoría antropológica y los dispositivos anclados en los regímenes de estatalidad, al tiempo que las categorías y conocimientos indígenas que explican estos procesos no son tenidos en cuenta. De esta manera, las resistencias cotidianas que responden a tales dispositivos dentro de los marcos posibles de acción permanecen ocultas en los intersticios de la teoría y, muchas ve-

nas (ReNaCI) del Instituto Nacional de Asuntos Indígenas (INAI). En el 2014, el Pueblo Yagán conformó la comunidad Paiakoala en Ushuaia. Desde entonces, comenzaron un largo viaje, entre oficinas gubernamentales, archivos, papeles y memorias, para demostrar sus lazos de continuidad con los antepasados. Finalmente, en marzo de 2021, lograron también su personería jurídica y el Estado argentino reconoció su preexistencia.

6 Bartolomé (2003: 174) explica que el término etnogénesis "ha sido utilizado tradicionalmente para dar cuenta del proceso histórico de la configuración de colectividades étnicas, como resultado de migraciones, invasiones, conquistas o fusiones". Revitalización étnica, por otro lado, refiere, según el autor, a las colectividades lingüística y culturalmente afines que se unifican agenciando una unidad que daría origen a una serie de naciones sin Estado, como el caso de los guaraníes (2003: 175). 
ces, no son interpretados como "resurgimiento"7 (Cornell 1988) porque no se encuadran en las ideas más tradicionales de la lucha política.

En un dossier en el que tuve la oportunidad de participar en el 2017, Mariela Eva Rodríguez realiza un breve estado del arte, en el que analiza los términos "etnogénesis", "reemergencia" y "resurgimiento indígena" y sus contextos de discusión. Propone reflexionar sobre la multiplicidad de sentidos que adquiere el concepto de etnogénesis y, por lo tanto, sobre sus limitaciones como categoría analítica. Con la intención de disminuir los ruidos generados por tal polisemia, en diálogo con los posicionamientos de los charrúas de Uruguay, con los trabajos de Gustavo Verdesio (2014) y de Axel Lazzari (2011), restringe el concepto de "reemergencia" para referir exclusivamente a la situación de los "pueblos a los que los dispositivos hegemónicos declararon 'extintos' - $\mathrm{o}$ 'en extinción' - y que, en el presente, se organizan y participan en la arena pública como miembros de colectivos indígenas" (Rodríguez 2017: 1). Es así que el proceso de "reemergencia" de un pueblo indígena, según Rodríguez, suele yuxtaponerse con procesos de "resurgimiento", de acuerdo con la acepción de Cornell (1988) y, a su vez, serían parte de los procesos de "etnogénesis", en caso de tomar las definiciones generales de la compilación de Hill (1996). En síntesis, es en este sentido que recurro al concepto de "reemergencia" - para referirme a los pueblos a los que la hegemonía consideró extintos y que en el presente se organizan políticamente (lo que Bartolomé califica como etnogénesis) - que, tal y como argumenta Lazzari (2017), es un término que permite enmarcar los procesos de fuerte discontinuidad y resurgir de la experiencia subjetiva indígena.

Una imagen útil para pensar en la experiencia de la reemergencia desde abajo es la figura del "viaje de vuelta" (Pacheco de Oliveira 1998), mencionada en la introducción, que es una estrategia para superar las interpretaciones dicotómicas primordialistas e instrumentalistas, y es también una imagen más cercana a estos procesos desde los términos y objetivos políticos de los indígenas de Tierra del Fuego en distintos momentos históricos. La idea de viaje de vuelta supone una dinámica doble que sería propia de los procesos identitarios, a saber: un retorno al "origen" y una trayectoria como movimiento y como camino recorrido. Pero también se trata de un viaje "para ser", una experiencia de subjetivación política que, al mismo tiempo, supone un destino que no tiene que ver tanto con el "rescate nostálgico del pasado" (Pacheco de Oliveira 1998: 65), sino que es una estrategia para "ser juntos" (Massey 2005; Briones y Ramos 2016) y enfrentar el presente de desigualdad. Esta idea, permite también pensar en distintos itinerarios o resistencias posibles y en otro tipo de relaciones e interconexiones en las luchas indígenas que se presentan, en este caso, en derroteros a través de intersticios porosos y fragmentados. A su vez, supone viajes a través de espacios, tiempos y huellas en los que generalmente las etnógrafas oficiamos como pasajeras.

\footnotetext{
Interesado en analizar el activismo indígena en Estados Unidos desde la década de 1960, Cornell (1988: 72) explica los procesos de formación de grupos y colectividades como resultado de la acción colectiva, atendiendo en su análisis tanto a "las fuerzas impersonales del cambio histórico" como a las respuestas colectivas frente a tales estructuras y las agencias humanas concretas de resistencia. Define dos procesos vinculados al resurgimiento contemporáneo de los indígenas: la indianización -que refiere a la emergencia de una consciencia supratribal-y la tribalización -que refiere al proceso a partir del cual los indígenas llegaron a convertirse en organizaciones-.
} 


\section{Traumas, fantasmas y el retorno de lo reprimido}

La provincia de Tierra del Fuego es un territorio marcado por un doble trauma ${ }^{8}$. En primer lugar, el trauma de la violencia colonial genocida que operó en el marco del avance de los estados nacionales argentino y chileno sobre sus fronteras internas, que para los indígenas significó el despojo de sus territorios, sus lenguas, sus hijos, sus vidas e incluso de sus muertos. Cuando mis interlocutores selk'nam mencionan la continuidad del genocidio en la actualidad, refieren a la dialéctica entre ese pasado y el presente; un presente en el cual se ven diariamente avasallados en sus derechos. Por otra parte, el genocidio y el colonialismo explican en parte las crisis de identidad, los miedos, los dolores y los resentimientos, sus propios interrogantes acerca de ser y no ser indígenas y las situaciones de conflicto y violencias en la vida cotidiana.

El trauma del genocidio también nos permite pensar en la crisis ontológica que atraviesa el discurso de la fueguinidad ante el retorno de los indígenas "extintos", tal y como sugiere Gustavo Verdesio (2020) para la reemergencia charrúa en Uruguay. Este autor suma a dicho país -y también a la región pampeana patagónica de Argentina y el sur de Chile- entre los casos de colonialismo de colonos (settler colonialism) que suelen incluir a Australia, Estados Unidos, Canadá y Nueva Zelanda. De acuerdo con Lorenzo Veracini (2011), el modelo del colonialismo de colonos se caracteriza, entre otras cosas, por la ocupación territorial como si fuera tierra vacía, el desplazamiento y exterminio de los indígenas que opusieron resistencia, la asimilación de los sobrevivientes y la amnesia por parte de los descendientes de colonos de la violencia en la que se sustentan sus privilegios actuales. Éste es un tipo de colonialismo particular, señala Verdesio (2014), diferente al que se dio en otros contextos coloniales basados en la obtención de plusvalía en regímenes organizados de trabajo forzado, tal como ocurrió por ejemplo en el Noroeste argentino. En las regiones donde la base de la colonización fueron las políticas de exterminio y de asimilación, continúa el autor, la reemergencia de los pueblos indígenas imaginados como extintos cuestiona los principios de la legitimidad de la soberanía del Estado-Nación y, por lo tanto, es frecuentemente resistida, dejando al descubierto la vigencia de la acumulación primitiva como proceso que necesita ser reafirmado todos los días.

En Tierra del Fuego, los sobrevivientes de las campañas de exterminio fueron incorporados a la nación mediante diversos dispositivos, a los cuales los indígenas resistieron mediante estrategias de "apaisanamiento" (Vidal 1993; Gerrard 2017); los colonos, a su vez, devinieron en pioneros o "antiguos pobladores" hace alrededor de cuarenta años. Por lo tanto, para que resulte comprensible en el ámbito local, optamos por la traducción "colonialismo de pioneros". Las narrativas fundacionales proponen una imagen armónica del encuentro entre los colonos y los indígenas, que tiende un manto de silencio sobre una serie de acontecimientos oscuros en la historia regional. Esta imagen de concordia se hace presente, incluso, en las perspectivas de algunos académicos y legos bienintencionados, entre los que se encuentran aquellos que, si bien reconocen que hubo políticas de exterminio, sostienen por ejemplo, que la evangelización salesiana habría tenido el objetivo de "proteger" a los indígenas de

8 Con el concepto de "trauma colectivo" me refiero al "efecto que, para los mecanismos tradicionales de recepción histórica y de representación de la identidad de un grupo humano, tienen ciertos eventos del siglo pasado" (Pérez Baquero 2016). 
los estancieros y de los buscadores de oro, y ocultan así el hecho de que la misión salesiana fue una de las instituciones que hizo posible la colonización.

Pero para comprender el contexto en el que los pueblos indígenas reemergen en Tierra del Fuego es preciso volver sobre un segundo trauma, a saber: el boom poblacional ocurrido con posterioridad a la sanción de la Ley de Régimen de Promoción Industrial $N^{\circ} 19.640$ de 1972, que produjo un aluvión migratorio que impactó en un aumento exponencial de la población ${ }^{9}$. Este proceso tuvo efectos en el corto y largo plazo, tanto en los indígenas - que asistían a una novedosa forma de invisibilización, al tiempo que los mayores se convertían en "últimos onas" y en mitos de origen provincial-, como en las familias pioneras cuyo poder se veía disputado por los recién llegados, e incluso en los migrantes que arribaron en ese entonces y que pretendían posicionarse en las estructuras del aparato de la provincia en ciernes (Vidal 1993).

La historia oficial y la "identidad fueguina" fueron configuradas en torno a la negación de la diferencia, y así se ocultó la desigualdad bajo la imagen de una unidad sociocultural. Como en el caso de Santa Cruz, analizado por Mariela Eva Rodríguez (2010, 2016), una serie de dispositivos - estatales, religiosos y científicos- construidos a partir de prejuicios racistas, colonialistas y nacionalistas, convergieron en una "formación discursiva de la extinción" en la que los indígenas de Tierra del Fuego fueron ubicados en la prehistoria y apropiados como el pasado de toda la provincia. Hernán Vidal (1993) argumentó al respecto que la apropiación de los indígenas para la construcción de un pasado compartido de "todos los fueguinos" se erigió sobre la base de la producción de "imágenes etnográficas" proyectadas por parte de una academia que la llevó más allá de sus fronteras: se vieron reflejadas no sólo en las políticas patrimoniales, sino también en las expresiones artísticas populares y en los espacios urbanos, que han sido escenario de disputas por la construcción de hegemonía entre los distintos sectores de migrantes, los recién llegados y los devenidos con la llegada de éstos últimos en "antiguos pobladores".

Desde entonces, los indígenas recorren las ciudades fueguinas como "fantasmas", es decir, como presencias espectrales materializadas en nombres de calles, monumentos a los indígenas "desaparecidos", fotografías, murales y edificios públicos promovidos por las elites de migrantes que instituyeron con éxito el mito fundacional de la nueva provincia. Así, estos migrantes lograron posicionarse en el espacio social estableciendo un lazo de continuidad con el pasado indígena, al tiempo que elegían nombres indígenas para sus hijos y reclamaban para sí una profundidad histórica mayor a la de los pioneros, a quienes señalaron como culpables del genocidio y la extinción de los pueblos originarios (Vidal 1993).

Esas configuraciones comenzaron a ser cuestionadas con la movilización indígena iniciada a mediados de la década de 1980, cuando paulatinamente se iban haciendo visibles en la arena pública y se iban distanciando -aunque nunca completamente- de la imagen fantasmática que sobre ellos recaía. Habilitado por las legislaciones de mediados de los años ochenta y noventa -como la Ley nacional $\mathrm{N}^{\circ} 23.302$ y la reforma de la Constitución Nacional en 1994 (art. 75 inc. 17)-, el Pueblo Selk'nam emprendió un "viaje de vuelta", y en el transcurso de la tramitación de la personería jurídica ante el Instituto Nacional de Asuntos Indígenas (INAI) fueron organizándose como comunidad Rafaela Ishton. Este viaje no fue sencillo en miras

La población total en el lado argentino de la isla pasó de 13.527 habitantes en 1970 a 127.205 en 2010 (INDECDGE y C.). 
a los prejuicios anteriormente mencionados, a los que se sumaron la imposición de la necesidad de diferenciarse de la normalidad instituida por el Estado-Nación; una diferencia que, como explica Claudia Briones (2016), está anclada en una serie de ideas preconcebidas, tales como la ancestralidad y la preservación de la cosmovisión y la memoria en la que estarían fundadas, que habrían de ser propias y diferentes a las de la sociedad no indígena. Por otra parte, siguiendo a esta autora, en Argentina rigieron también otras imposiciones al respecto de la diferencia en las relaciones sociales, económicas y políticas, tales como la obligación de elaborar un estatuto, de especificar los mecanismos formales para la membresía, y de determinar una forma de designación y duración del mandato de autoridades, entre otras.

Todo lo anterior, sumado a la presunción de que las "comunidades" debían conformarse por un conjunto de familias emparentadas, un pasado común demostrable y un presente de convivencia, influyó en los caminos que en ese entonces asumieron los selk'nam en busca de archivos y libros de Historia y Antropología para demostrar la veracidad de sus historias y vínculos genealógicos. Produjeron, también, una serie de "entextualizaciones" (Bauman y Briggs 1990) para explicar su persistencia en el territorio que otrora fuera la única "reserva" indígena en el Territorio Nacional de Tierra del Fuego.

Lazzari (2017) establece una relación entre el concepto de reemergencia y los de fantasma y fetiche. Con la idea de "fantasma" designa una experiencia de movimiento de aquello que está situado en un espacio liminal entre el mundo de los vivos y de los muertos, entre ausencias y presencias en un proceso de eterno distanciamiento y retorno. Los indígenas reemergentes son acosados por este fantasma, y de allí su malestar y sufrimiento a la hora de afrontar los dispositivos de reconocimiento que les exigen identidades fijas y específicas.

Como explica Verdesio (2017), a diferencia del fantasma (ghost), que supone una presencia incorpórea o inmaterial, el revenant de la tradición francesa admite el retorno temporal, la emergencia del mundo de los muertos al mundo de los vivos -o la reemergencia de un pueblo que se creía extinto-; tal y como explica Lazzari (2017: 47), el retorno del revenant es un "recordatorio de una deuda impaga", y también un indicio del fracaso civilizatorio que intentó a todas luces eliminar o asimilar la diferencia, pero que no contaba con "el retorno de lo reprimido" (Verdesio 2020). En este sentido, la negación de la existencia de los indígenas en el presente -que continúa siendo parte de lo dóxico en la sociedad fueguina- se vincula a la negación del colonialismo, puesto que la colonización habría quedado en el pasado y los responsables del genocidio serían otros que ya habrían sido señalados como tales. Es por esto que, tal y como explica Verdesio (2020) retomando a Wolfe, la estrategia de resistencia indígena más efectiva para enfrentarse al colonialismo de pioneros es permanecer en el territorio conquistado, lo que les habilita a afirmar su preexistencia al Estado nación y su persistencia, a pesar de la histórica persecución y de los intentos de exterminio.

Este tipo de colonialismo es, con todo, una de las formas más atroces de dominación colonial, puesto que procura la eliminación de las poblaciones indígenas y establece una serie de mitos fundacionales que asocian el establecimiento de pioneros y misioneros como una fuente de progreso y prosperidad. Esta situación explica por qué la aparición de los indígenas en la esfera pública es continuamente resistida, y también por qué los procesos de subjetivación política indígena tienen fuertes costos emocionales y sociales para quienes deciden emprender el "viaje de vuelta" con la intención de reencontrarse con las huellas de los antepasados. 


\section{Arqueologización, culturalismo y resistencias}

Tal y como argumentó Vidal (1993), en el territorio fueguino, los procesos de arqueologización hegemonizaron un relato arqueológico unívoco del pasado, que excluyó a los indígenas del presente y los proyectó hacia la prehistoria. A pesar de la riqueza de su trabajo, no tuvo en consideración que las categorías que reproducen esa imagen pretérita acaban oprimiendo a su ser en el presente: convertidos en textos sagrados, los indígenas aparecen no sólo en los lugares de producción de conocimiento, sino también en los museos y galerías bajo la forma de preciadas mercancías, objetivados en imágenes de cuerpos pintados o en materiales líticos que imponen una sujeción por parte del conocimiento ilustrado, y que como contrapartida, hace evidentes una serie de agenciamientos y resistencias.

Estas imágenes hegemónicas de alteridad definen los estándares de autenticidad a partir de las cuales la pertenencia indígena es juzgada, y obliga a las comunidades y personas que afirman tales pertenencias a privilegiar las continuidades sobre los cambios sociales, lo que paradójicamente instaura una lógica que presume como única posibilidad la pérdida de la pertenencia. La paradoja de estas relaciones de continuidad-discontinuidad enmarcadas en los procesos hegemónicos reside en el énfasis que la Arqueología otorga a la construcción del estereotipo del indígena paleolítico y, en contrapartida, a la experiencia de discontinuidad y reemergencia en un régimen de historicidad percibido como un proceso histórico continuo que los posiciona siempre en un lugar sospechado.

La Etnología y la Antropología tuvieron mucho que ver con estas proyecciones en la medida en que instalaron la idea de la conjunción entre "cultura" e "identidad"; o de "identidad cultural" que, en el marco de la hegemonía del multiculturalismo ${ }^{10}$, presume que la diferencia debe ser clara y visible para atribuir un reconocimiento legítimo de la pertenencia originaria (Briones 2016: 59). "Nosotros no conservamos nuestra cultura, la perdimos y tenemos que recuperarla", me dijo una vez Miguel Pantoja, joven del pueblo selk'nam, apenas nos conocimos en 2016. Esta frase -como terminó concluyendo después de una serie de largos intercambios que entablamos en torno a los conceptos de cultura y hegemonía- es la reproducción de un discurso que, entendido como práctica social (Foucault 1992), ha contribuido históricamente a la subalternización de su pueblo. El discurso científico, en tanto dispositivo de

10 Charles Hale (2001) define el "multiculturalismo neoliberal" como una doctrina que promueve los derechos de los pueblos indígenas de forma sustantiva pero limitada. Así, al administrar las diferencias, el Estado favorece determinadas expresiones de etnicidades que están habilitadas, al tiempo que restringe expresiones y derechos que entran en contradicción con los intereses económicos trasnacionales. Para el autor, estos escenarios no siempre conllevan conflictos con agencias estatales y de desarrollo, sino que también puede constituirse en un terreno de negociación favorable a sus reclamos. Stuart Hall (2000), por su parte, distingue entre multiculturalidad y multiculturalismo. Mientras que el primero es un adjetivo que describe sociedades heterogéneas en las que conviven personas diferentes sin estar segregadas, el multiculturalismo refiere a toda una serie de políticas, ideas y actitudes con respecto a tales diferencias. A partir de esta separación analítica y la distinción entre diferentes multiculturalismos, autores como Eduardo Restrepo (2012) argumentan que el multiculturalismo debe ser promovido y contestar las imposiciones dominantes de las políticas de la diversidad. Sin embargo, otros autores como Cristóbal Gnecco (2017) mantienen una postura más radicalizada. Este último sostiene de forma muy convincente que la convivencia armónica entre una variedad de géneros y etnias - donde antes tan solo eran visibles los sujetos heterosexuales y nacionales- es uno de los mayores logros del capitalismo contemporáneo, que promueve una heterogeneidad despojada de las relaciones de poder que la constituyen. Propone entonces pensar en la alteridad como devenir y distingue entre la "diversidad" como mercancía promovida por el multiculturalismo y la "diferencia" como la emergencia de sujetos enredados en tensiones y antagonismos. 
saber-poder (Foucault 2002), redujo a los clasificados como "descendientes"11 a un status de impureza, con la consecuente duda generalizada sobre la legitimidad de su propia existencia.

Es así como la conceptualización de la "cultura" como un conjunto fijo de rasgos de "poblaciones" en "vías de extinción" o "extintas" se hace presente, de forma más o menos explícita, en la gran mayoría de las investigaciones que remiten al pueblo selk’nam. Estas conceptualizaciones, más allá de los esfuerzos de algunos investigadores por historizar, dificultaron -o impidieron- el desarrollo de una explicación consistente de la complejidad del cambio social en el escenario insular.

Los etnógrafos (Gusinde 1982; Chapman 2007) determinaron fronteras étnicas con delimitaciones territoriales específicas -las cuales dejaron de lado las migraciones, diásporas y fronteras- y establecieron variables raciales y culturales aisladas en unidades pensadas como "puras". Al respecto, Rodríguez (2010) explica que los rótulos impuestos por la academia decimonónica se colaron en las taxonomías del siglo XX. Entonces, las "tribus" descriptas por los viajeros del siglo XIX se volvieron "grupos étnicos" en el siglo XX; entidades culturales-raciales diferenciadas e inmutables, atrapadas en un eterno "presente etnográfico" y valoradas según imágenes idealizadas de "pureza". Los cambios en las prácticas de la vida cotidiana pasaron a ser leídos como pérdidas, degeneración y extinción. Es más, como argumenta esta autora retomando a Silverstein, estas taxonomías crearon efectos de realidad; no sólo impusieron identidades, sino que también orientaron políticas estatales.

Las teorías sobre la muerte de las culturas encierran una concepción esencialista de la alteridad. Tal como ocurrió con los tehuelches y otros pueblos indígenas de la región, la ecuación de la desaparición de los selk'nam ha sido discursiva en el sentido que Foucault le otorga a término: una desaparición en la que confluyen diversos dispositivos. Es decir, como sostiene Rodríguez (2010, 2016), desaparecieron porque dejaron de ajustarse al modelo evolucionista de la raza y la cultura construido en el siglo XIX. Retomando el caso de Tierra del Fuego, resulta evidente que la cultura así definida -como una esencia que debería mantenerse inmutable a través del tiempo-surge de una matriz de pensamiento que dificulta a los indígenas alejarse de los estereotipos que moldean las performances; estereotipos que, además, los subalternizan. Para los historiadores y arqueólogos, el rasgo por excelencia de estas esencias suele ser el nomadismo, la caza y la recolección, la vestimenta y toda una serie de diacríticos fuertemente instalados en los discursos sociales. Los selk'nam, al igual que los tehuelches de la Patagonia austral, también quedaron "atrapados en una paradoja ligada a las maquinarias territorializadoras, de acuerdo con la cual la alta movilidad conducía a la extinción, en tanto que el emplazamiento en sitios fijos (ya sean en las 'reservas' o en las ciudades) conducía a la 'pérdida' de sustancia original definitoria de aboriginalidad, y/ o al 'degeneramiento"” (Rodríguez 2010: 157). Estas premisas se sustentan en leyes evolutivas de alcance general, de acuerdo con las cuales el "hombre primitivo" debía alcanzar los peldaños superiores (sedentarismo, agricultura, pastoreo, ganadería, propiedad privada, vida urbana). La supuesta "incapacidad" de los indígenas para abandonar el nomadismo y las prácticas tradicionales -que es en realidad una incapacidad interpretativa de quienes intentan explicar los

11 A diferencia de otras naciones latinoamericanas, en Argentina prevaleció una ideología que no dio como resultado la creación de "mestizos", sino de "descendientes", considerados desde los dispositivos hegemónicos como impuros, aculturados, etc. (Rodríguez 2016). 
cambios a partir de leyes generales- condujo a la conclusión de que los selk'nam se "extinguieron" porque "cambiaron", y ya no presentaban los rasgos esenciales que pretendía -y pretende- esta perspectiva científica.

En el proceso de fortalecimiento identitario y comunitario, los selk'nam y los yaganes han ido elaborando sus posicionamientos en una relación dialéctica con las imágenes hegemónicas proyectadas por la ciencia y, a su vez, planteando una serie de demandas vinculadas a la autorrepresentación. En la actualidad, muchas personas y familias que se autoadscriben como indígenas o "descendientes" nominaciones que varían según las diferentes experiencias- encuentran en las publicaciones de los antropólogos información y fotografías que les permiten reconstruir lazos con sus antepasados, así como también reconstituir saberes, prácticas y formas de ser y existir en el territorio arrebatado por los Estados, y que poco después fue privatizado. Walter Benjamin (2008: 37) afirma que "sólo a la humanidad redimida le concierne enteramente su pasado (...) [es decir] se le ha vuelto citable su pasado en cada uno de sus momentos". Esta capacidad de "citar" el pasado habilita en ese movimiento una resignificación del presente y una subversión del lugar subalterno.

\section{Reflexiones finales}

El estudio de la historicidad fueguina a partir del trauma colonial, el colonialismo de pioneros y el retorno de lo reprimido, permite reflexionar en otra clave acerca de los problemas sociales, políticos y culturales de la región y, asimismo, resituar y comprender los miedos, las emociones y los dolores, los conflictos y la violencia. Por otro lado, dicho abordaje hace evidentes las resistencias intersticiales en las que los indígenas buscan reconstruir la dignidad que el colonialismo les habría arrancado a pedazos (Fanon 1963), y advertir así la lucha emprendida para "ser juntos" (Massey 2005; Briones y Ramos 2016), para "reconstruir la casa" y, en simultáneo, cuestionar las narrativas fundacionales del territorio provincial, la opresión y el racismo colonialista y nacionalista.

Si bien la Antropología impuso una serie de clasificaciones etnológicas culturalistas y preterizantes enraizadas en los dispositivos coloniales, es también una fuente de información valorada, porque permite reconstituir dialécticamente el pasado para explicar el presente. En relación con la etnografía colaborativa (Rappaport 2005) que realizo en Tierra del Fuego, resulta evidente que el diálogo de saberes habilita otras alternativas para desafiar, discutir y reelaborar los términos y las categorías académicas desde conceptualizaciones y conocimientos propios (ver Pantoja 2018), los cuales se suman a las formas creativas en las que las diferentes generaciones han enfrentado el poder del Estado y la ciencia, y han resistido al colonialismo de pioneros y a la institucionalización del relato de la historia oficial.

Frente al multiculturalismo y la hegemonización de políticas de la diversidad que fomentan una convivencia armónica y respetuosa, sin conflictos ni oposiciones, los selk'nam y los yaganes demandan "hablar" desde sus propios lugares de enunciación (Spivak 1988) y, en ese proceso, muchas veces se expresan antagonismos que trascienden la mera celebración de la diversidad. También reclaman su participación en los procesos de producción de conocimiento histórico y antropológico porque, como me han explicado muchas veces, "la verdadera histo- 
ria" debe ser contada en primera persona, dado que se trata de una lucha por el presente y el porvenir. Tal y como expresó Miguel Pantoja: "ayer fue el silencio a balazos, hoy somos la memoria que persiste, los aires de lucha y las lenguas que no han podido callar" 12 .

\section{Referencias}

Bartolomé, Miguel Alberto. 2003. «Los pobladores del 'Desierto': genocidio, etnocidio y etnogénesis en Argentina». Cuadernos de Antropología Social 17: 162-189.

Bauman, Richard y Charles Briggs. 1990. «Poetics and performance as critical perspectives on language and social life». Annual Review of Anthropology 19 (1): 59-88.

Benjamin, Walter. 2008. Tesis sobre la historia y otros fragmentos. México: Ítaca, Universidad Autónoma de la Ciudad de México.

Briones, Claudia. 2016. «Caminos de enraizamiento en la mapu: procesos de formación de comunidad en la Norpatagonia argentina», en Parentesco y política. Topologías indígenas en la Patagonia, Claudia Briones y Ana Ramos, comps., pp. 53-69. Viedma: Editorial Universidad Nacional de Río Negro.

Briones, Claudia y Ana Ramos. 2016. «Agenciando formas de ser juntos en contextos interculturales: anudamientos de memoria, parentesco y política», en Parentesco y política. Topologías indígenas en la Patagonia, Claudia Briones y Ana Ramos, comps., pp. 11-51. Viedma: Editorial Universidad Nacional de Río Negro.

Chapman, Anne. 2007. Los selk'nam, la vida de los onas en Tierra del Fuego. Buenos Aires: Emecé.

Cornell, Stephen. 1988. The Return of the Native: American Indian Political Resurgence. Nueva York, Oxford: Oxford University Press.

Fanon, Frantz. 1963. Los condenados de la tierra. México: Fondo de Cultura Económica.

Foucault, Michel. 1992. El orden del discurso. Buenos Aires: Tusquets.

- 2002. La arqueología del saber. México: Siglo XXI Editores.

Gerrard, Ana Cecilia. 2017. «Silcha, el agente de policía: una aproximación a la conquista simbólica en el Territorio de Tierra del Fuego (1920-1940)». Conversaciones del Cono Sur 3 (1): 60-68.

Gnecco, Cristóbal. 2017. «Multivocalidad, años después», en Antidecálogo. Diez ensayos (casi) arqueológicos, Cristóbal Gnecco, pp. 21-35. Popayán: Universidad del Cauca, JAS Arqueología, Ediciones del Signo.

Gusinde, Martin. 1982. Los indios de Tierra del Fuego. Buenos Aires: Centro Argentino de Etnología Americana.

Hale, Charles R. 2001 «Does Multiculturalism Menace? Governance, Cultural Rights and the Eclipse of 'Oficial Mestizaje'». Cuzco: Workshop Cultural Agency in the Americas: Language, Ethnicity, Gender, and Outlets of Expression.

Hall, Stuart. 2010. «La cuestión multicultural», en Sin garantías. Trayectorias y problemáticas en estudios culturales, Stuart Hall, pp. 583-618. Popayán, Lima, Quito: Universidad Andina Simón Bolívar, IESCP, Pontificia Universidad Javeriana, IEP, Envión Editores.

Hill, Jonathan. 1996. History, Power, and Identity: Ethnogenesis in the Americas, 1492-1992. Iowa City: University of Iowa Press.

12 “A hacha, cuña, golpe y remington". Texto que acompañó la instalación "Susurros del viento" del artista José María Martin en el Museo Provincial Yaganes, junio de 2019. 
- 2009. «History, Power and Identity: Amazonian Perspectives». Acta Historica Universitatis Klaipedensis XIX, Studia Anthropologica 3: 25-47.

Lazzari, Axel. 2011. Autonomy in Apparitions: Phantom Indian, Selves, and Freedom (on the Rankülche in Argentina). Tesis doctoral, Department of Anthropology, Columbia University. Ann Arbor: ProQuest Dissertations and Theses.

- 2017. «¿Por qué el término reemergencia indígena?: Acentuando dis-continuidades y reemergencias». Conversaciones del Cono Sur 3 (1): 43-50.

Massey, Doreen. 2005. For Space. Londres: Sage Publications.

Pacheco de Oliveira, João. 1998. «¿Uma etnologia dos índios misturados? Situação colonial, territorializacao, e fluxos culturais». Mana 4 (1): 47-77.

Pantoja, Miguel. 2018. «Nunca los últimos, siempre los primeros», en A través de sus cenizas. Homenaje a Hernán J. Vidal, Mariela Eva Rodríguez, Ana Cecilia Gerrard y Magdalena Vidal, eds., pp. 372-383. Ibarra: Edición Preliminar Impresa.

Pérez Baquero, Rafael. 2016. «Historia y trauma colectivo: límites, usos y abusos». Oxímora. Revista Internacional de Ética y Política 8: 131-147

Rappaport, Joanne. 2005. Intercultural Utopias: Public Intellectuals, Cultural Experimentation, and Ethnic Pluralism in Colombia. Durham: Duke University Press.

Restrepo, Eduardo. 2012. “¿El multiculturalismo amerita ser defendido?», en Autonomías territoriales: experiencias y desafios, Juan G. Ferro y Gabriel Tobón, comps., pp. 19-39. Bogotá: Pontificia Universidad Javeriana.

Rodríguez, Mariela Eva. 2010. De la “extinción” a la autoafirmación: procesos de visibilización de la Comunidad Tehuelche Camusu Aike (provincia de Santa Cruz, Argentina). Tesis Doctoral, Faculty of the Graduate School of Arts and Sciences, Georgetown University, Washington, D.C.

-. 2016. "“Invisible Indians", "Degenerate Descendants": Idiosyncrasies of Mestizaje in Southern Patagonia», en Shades of the Nation: Rethinking Race in Modern Argentina, Paulina Alberto y Eduardo Elena, eds., pp. 127-154. Cambridge: Cambridge University Press.

- 2017. «Excepcionalidad uruguaya y reemergencia charrúa». Conversaciones del Cono Sur 3 (1): 28-36.

Rodríguez, Mariela Eva, Celina San Martín y Fabiana Nahuelquir. 2016. «Imágenes, silencios y borraduras en los procesos de transmisión de las memorias mapuches y tehuelches», en Memorias en lucha. Recuerdos y silencios en contextos de subordinación y alteridad, Ana Ramos, Carolina Crespo y Alma Tozzini, eds., pp. 111-140. Viedma: Universidad Nacional de Río Negro.

Spivak, Gayatri Chakravorty. 1988. «Can the subaltern speak?», en Marxism and the Interpretation of Culture, Cary Nelson y Lawrence Grossberg, eds., pp. 361-365. Urbana: University of Illinois Press.

- 2013. Sobre la deconstrucción. Introducción a De la gramatología de Derrida. Buenos Aires: Hilo Rojo Editores.

Veracini, Lorenzo. 2011. «Introducing Settler Colonial Studies». Settler Colonial Studies 1 (1): $1-12$.

Verdesio, Gustavo. 2014. «Un fantasma recorre el Uruguay: la reemergencia charrúa en un "país sin indios"». Cuadernos de Literatura XVIII-36: 86-107.

- 2017. «Comentarios sobre la mesa "Reemergencia indígena en los países del Plata: el caso de Argentina"». Conversaciones del Cono Sur 3 (1): 77-83.

- 2020. «Endless dispossession: The Charrua re-emergence in Uruguay in the light of settler colonialism». Settler Colonial Studies. https://doi.org/10.1080/2201473X.2020.1823752 
Vidal Espinoza, Hernán. 1993. «A través de sus cenizas. Imágenes etnográficas e identidad regional en Tierra del Fuego (Argentina)». Tesis de Maestría. Facultad Latinoamericana de Ciencias Sociales (FLACSO) sede Ecuador. http://www.flacsoandes.edu.ec/ libros/8614-opac. 